\title{
Characterization of the Physicochemical Properties of Different Biodiesel Samples
}

\author{
Maria Thais Vertonha ${ }^{1 *}$, Leonardo Almeida Delgado ${ }^{1}$, Gustavo Vinicius Bassi Lukasievicz ${ }^{1}$ \\ ${ }^{1}$ Universidade Tecnológica Federal do Paraná, Medianeira, Paraná, Brazil.
}

\begin{abstract}
For combustion engines to perform well, it is necessary that the fuel used be of high quality. Fuel quality can be analyzed through different physicochemical properties. This study presents comparisons between the values presented in literature, legislation and those obtained through experimental tests of different biodiesel samples. Biodiesel is a promising alternative of renewable energy obtained from raw material. The properties observed in this study are: Viscosity, density, cloud point, pour point and calorific value. The data explored by this work aims to bring solidification to the methodologies and equipment necessary for a better characterization of biodiesel.
\end{abstract}

Keywords: Biodiesel, vegetable oil, animal fat, ANP.

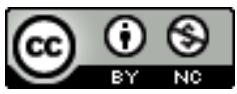

\footnotetext{
*Author for correspondence: mvertonha@gmail.com
} 


\section{INTRODUCTION}

Society has been suffering from air pollution due to a large scale of Greenhouse Gas Emissions that are produced during the combustion process of fossil fuels. As a result, new alternatives have emerged, such as biodiesel. This biofuel is produced by a process called transesterification. It is an association of vegetable oils or animal fat with an alcohol in the presence of a catalyst. In Brazil, studies in search of a new source of fuel derived from vegetable oils date back to $1895^{1}$.

Some properties of vegetable oils are similar to fossil diesel oil, which allows us to use them as fuels, however the direct use of these oils in the engine can generate complications in the its performance.

Some of the consequences that can be generated by prolonged use of vegetable oils in combustion engines are excessive carbon deposits in the engine, clogging of oil filters and injectors, impairment of engine durability, and a considerable increase in maintenance costs ${ }^{2,3}$.

In order to remedy such consequences, several processes have been developed to improve vegetable oils as fuels. The most widely used is the transesterification process, which has as its final product biodiesel, also known as green oil.

Biodiesel presents numerous advantages to diesel. Biodiesel is a less polluting fuel because it emits lower amounts of carbon monoxide and particulate matter ${ }^{4}$. In addition to being less toxic, it is biodegradable ${ }^{5}$. It has a higher flash point than diesel and thus has a low explosion risk 6 . It has two oxygen atoms in its molecule because it is an ester, therefore, a much smaller amount of oxygen is needed for combustion; biodiesel can be obtained from any oilseed; it improves lubrication in the ignition system, which reduces wear and can increase engine life; among so many qualities, its renewability can be mentioned as the main advantage ${ }^{7}$.

In addition to vegetable oils, biodiesel may also contain animal fat, which is derived from animal slaughter. The production of biodiesel from animal fat is economically satisfactory when comparing the low cost with the quantity of raw material offered. In addition, the disposal of this residue is not always carried out correctly, hence its reuse reduces negative environmental impacts.

The rheological and physicochemical study of biodiesel properties is extremely important for a near future, since studies show fossil oil depletion for the upcoming future.

The National Agency for Petroleum, Natural Gas and Biofuels (ANP) is responsible for implementing the national fuel and biofuel policy, as well as their quality specifications. According to ANP Resolution No. 45 of August 25, 2014, biodiesel is defined as a fuel composed of alkyl esters of long chain carboxylic acids, produced from the transesterification and/or esterification of greases, from fats of vegetable or animal origin, and that meets the specifications contained in Technical Regulation ANP No. 3/2014.

Given all the well-known problems of fossil fuels, the objective of this work is to characterize some physical properties, such as: pour point, cloud point, calorific value, density and dynamic viscosity of different biodiesels and compare them with the specifications of ANP 45/2014 Resolution ${ }^{8}$.

\section{MATERIAL AND METHODS}

Three samples of Biodiesel were obtained: the first sample consisting of (63\%) Soybean oil, (35\%) Animal Fat, (2.0\%) Methanol and represented in this work by BSGM; the second sample (60\%) Soybean Oil and (40\%) Animal Fat - BSG; and the third sample Soybean Oil, Cottonseed and Recovered Oils - BSA. The following 
biodiesel properties were analyzed: density, dynamic viscosity, calorific value, pour and cloud point.

\section{Density}

For density measurements, the Anton-Paar digital densimeter model DMA 5000 was used, where the reading accuracy in the density value is $0.000005 \mathrm{~g} / \mathrm{cm}^{3}$ and $0.01 \mathrm{~K}$ in the temperature controller. The measurements were performed at temperature range of $20^{\circ} \mathrm{C}$ to $90^{\circ} \mathrm{C}$, obtaining a reading at every $2^{\circ} \mathrm{C}$.

\section{Dynamic and kinematic viscosity}

The determination of the dynamic viscosity as a function of temperature was conducted in the Brookfield Rheometer, model DV-III Basic, using a cylindrical spindle (SC4-18) with fixed rotation of $40 \mathrm{rpm}$, operating with Brookfield temperature controller, model TC-602, in the range of $288 \mathrm{~K}$ to $363 \mathrm{~K}$, at $1 \mathrm{~K}$ intervals, with a 0.01 $\mathrm{K}$ error. Each sample was analyzed in triplicates.

To determine the kinematic viscosity, which is in the ANP standard, the ratio between the dynamic viscosity and the specific mass of the fluid must be calculated. The values of ANP Resolution No. 45 of August 25, 2014 can be seen in Table 1.

Table 1- Comparison of biodiesel specifications.

\begin{tabular}{lcc}
\hline Property & Unit & Biodiesel \\
\hline Density at $293.15 \mathrm{~K}$ & $\mathrm{~g} / \mathrm{cm}^{3}$ & 0.85 to 0.90 \\
$\begin{array}{c}\text { Kinematic viscosity at } \\
\text { 313.15 K }\end{array}$ & $\mathrm{mm}^{2} / \mathrm{s}$ & 3.00 to 6.00 \\
Pour point, max. & $\mathrm{K}$ & $278.15 *$ \\
\hline $\begin{array}{l}\text { *Lower value. Further, details in ANP Technical Regulation No. 3/2014, table II. } \\
\text { Source: Adapted from ANP Technical Regulation No. 3/2014. }\end{array}$
\end{tabular}

\section{Calorific power}

An IKA Works calorimetric pump, model c-2000 Basic was used. It was operated at $25^{\circ} \mathrm{C}$, accuracy of $0.1{ }^{\circ} \mathrm{C}$ and 15 bar of oxygen pressure, with a sample of approximately $0.5 \mathrm{~g}$. The analyses were performed in triplicates.

\section{Pour point and cloud point}

For the determination of the cloud and pour points of the samples, a thermostated bath was used, with a $0.1^{\circ} \mathrm{C}$ error in the control of temperature. The process for obtaining the cloud point was adapted from ASTM D2500. $6 \mathrm{ml}$ of each sample were added in separate test tubes and immersed in the thermostated bath without touching the bottom, the points were collected at $20^{\circ} \mathrm{C}$ to $-1{ }^{\circ} \mathrm{C}$, at $1{ }^{\circ} \mathrm{C}$ intervals by visual observation for 3 seconds at each degree.

Using the same bath, and similar methodology, with an adaptation of the ASTM D97 standard, the pour point was determined. The Pour Point is the temperature prior to which the pour of the sample was no longer observed by tilting the test tube horizontally, for the duration of 5 seconds. 
All the equipment used for the analyses mentioned in the methodology were properly calibrated according to the specifications of standard ABNT NBR ISO/IEC 17025.

\section{RESULTS AND DISCUSSION}

The results of this work are discussed below. Samples BSGM, BSG and BSA were analyzed with the purpose of evaluating the influence of the raw material on physicochemical behavior of the samples.

\section{Density}

The behavior and density values for the biodiesel samples can be seen in Figure 1 .

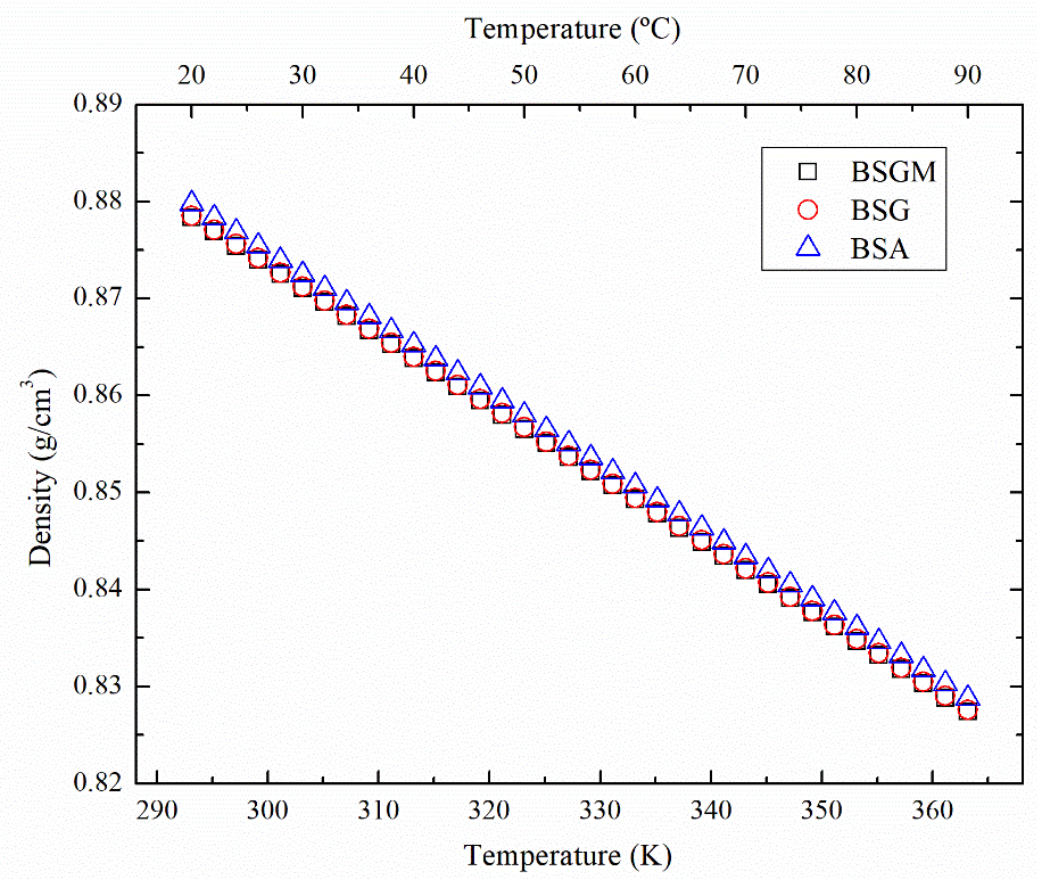

Figure 1- Temperature dependence of density for different biodiesel samples.

There is a linear decrease in density with temperature increase. The increase in temperature dilates the fluid, which undergoes an increase in its volume, but as it remains with its mass constant, the density decreases. The values found experimentally for the density are within the limits allowed by the Technical Committee No. 3 of 2014 of ANP Resolution No.45, as Table 2.

Table 2 - Relation of density values.

\begin{tabular}{cc}
\hline Biodiesel & Density at $\mathbf{2 0}{ }^{\circ} \mathrm{C}\left(\mathbf{g} / \mathbf{c m}^{\mathbf{3}}\right)$ \\
\hline Regulation value & 0.85 to 0.90 \\
BSGM & $0.878369 \pm 0.000005$ \\
BSG & $0.878505 \pm 0.000005$ \\
BSA & $0.879777 \pm 0.000005$ \\
\hline
\end{tabular}




\section{Dynamic Viscosity}

The data obtained for the dynamic viscosity is shown in Figure 2. It is noted that the higher the sample temperature, the smaller viscosity. By adjusting the exponential characteristic of the data collected by the rheometer, such behavior can be clearly observed.

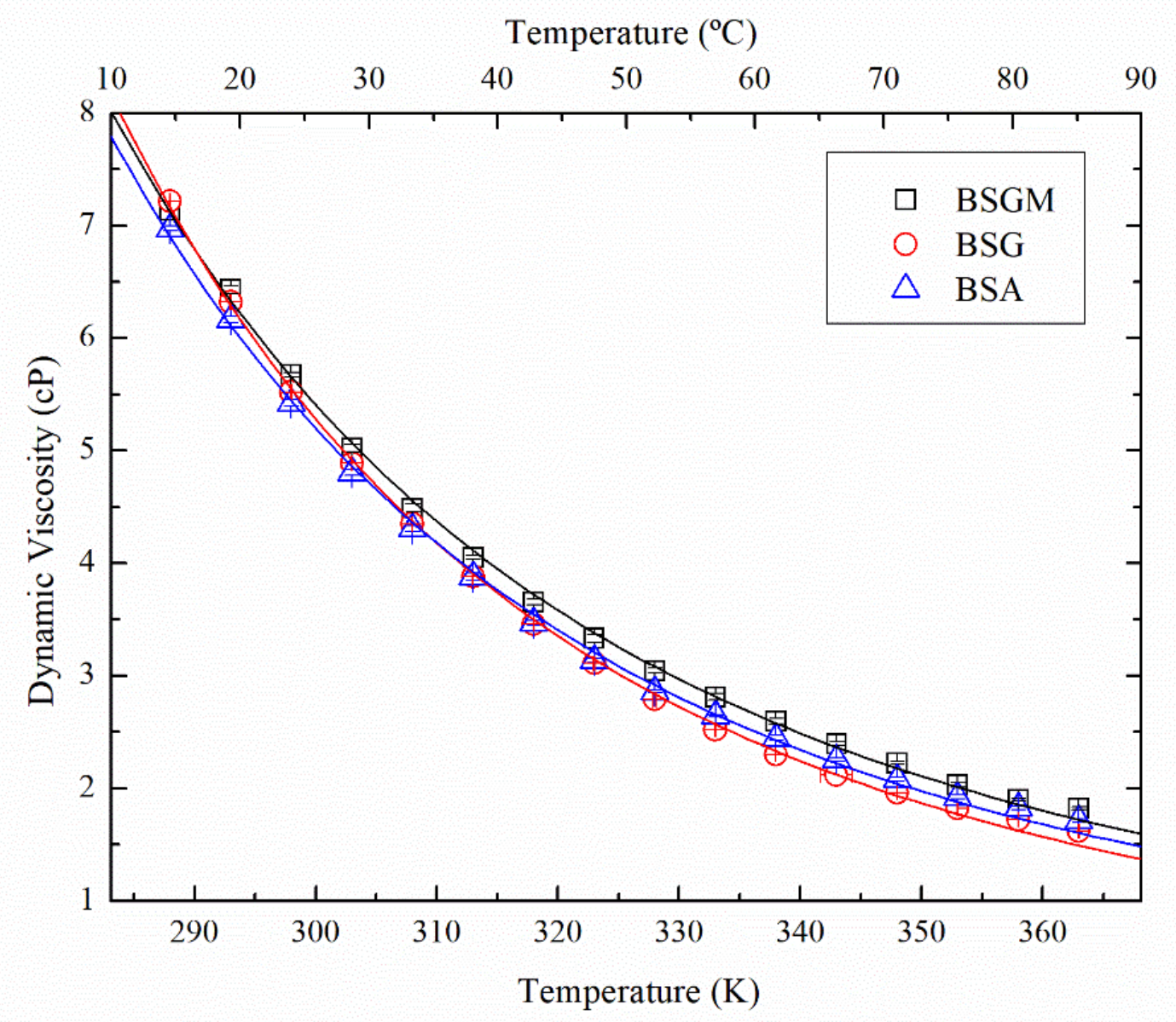

Figure 2- Dynamic viscosity of biodiesel samples as a function of temperature.

\section{Activation energy}

When applying a natural logarithm to the Arrhenius equation, it is possible to obtain a linearization, in which the activation energy is the angular coefficient of the line. Therefore, Figure 3 shows a small variation of the linear for high temperatures. Table 3 shows the activation energy obtained from the best curve fitting. The dynamic viscosity depends on the temperature; this dependency is proportional to the energy of activation. Thus, the rapid variation of viscosity with temperature results in high activation energy9 . 


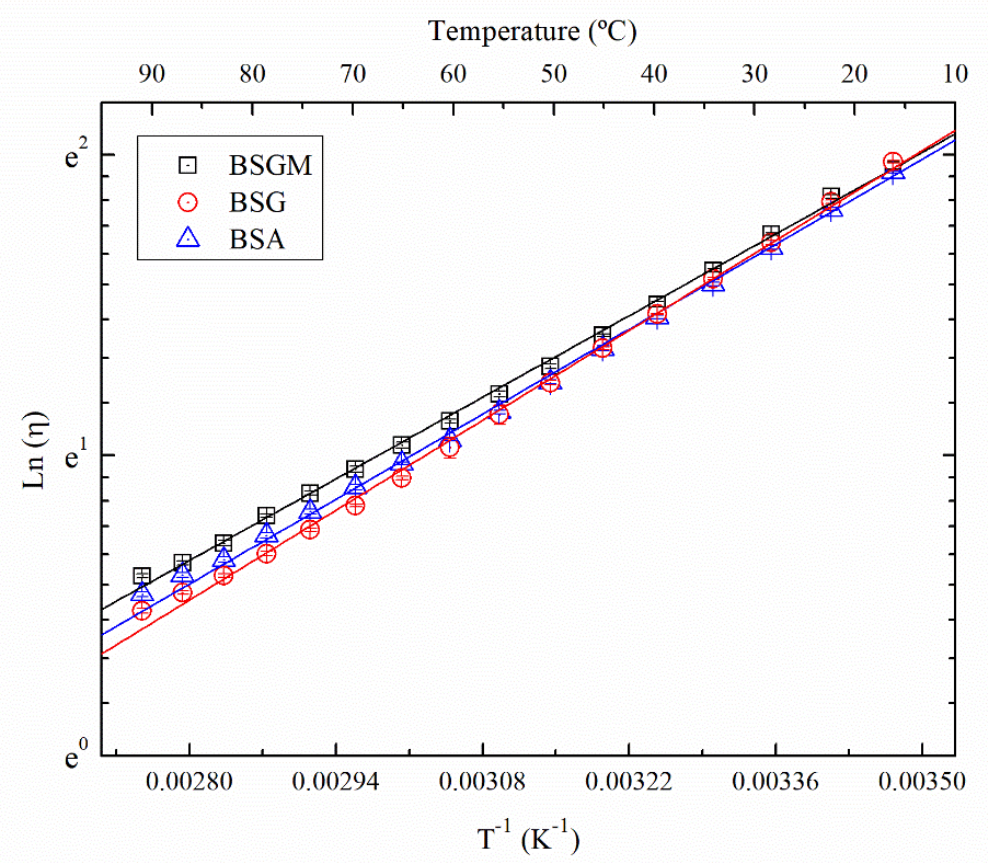

Figure 3- Natural logarithm of the dynamic viscosity as a function of the inverse of the temperature for biodiesel samples.

Table 3 - Activation energy of the analyzed samples.

\begin{tabular}{cccc}
\hline Sample & A (mPa.s) & Ea $(\mathbf{k J} / \mathbf{m o l})$ & $\mathbf{R}^{2}$ \\
\hline BSGM & 0.00838 & $16.1 \pm 0.2$ & 0.99867 \\
BSG & 0.00423 & $17.8 \pm 0.2$ & 0.99836 \\
BSA & 0.00620 & $16.8 \pm 0.2$ & 0.99817 \\
\hline
\end{tabular}

\section{Kinematic viscosity}

In ANP Resolution No. 45/2014 there are no specifications for dynamic viscosity values, however, the kinematic viscosity values are considered as standards for the quality of biodiesel. The kinematic viscosity can be obtained by the ratio of the dynamic viscosity to the density of the fluid. The properties values at $40^{\circ} \mathrm{C}$ can be observed in Table 4 . The three analyzed samples have values of kinematic viscosity within the parameters allowed by regulation.

Table 4 - Density, dynamic and kinematic viscosity of the biodiesel samples at $40^{\circ} \mathrm{C}$.

\begin{tabular}{cccc}
\hline Biodiesel & $\begin{array}{c}\text { Density } \\
\left(\mathbf{g} / \mathbf{c m}^{3}\right)\end{array}$ & $\begin{array}{c}\text { Dynamic Viscosity } \\
(\mathbf{c P})\end{array}$ & $\begin{array}{c}\text { Kinematic viscosity } \\
\left(\mathbf{m m} \mathbf{m}^{2} \mathbf{s}\right)\end{array}$ \\
\hline Regulation value & 0.85 to 0.90 & - & 3.00 to 6.00 \\
BSGM & 0.86383 & 4.052 & 4.691 \\
BSG & 0.86397 & 3.879 & 4.490 \\
BSA & 0.86523 & 3.879 & 4.483 \\
\hline
\end{tabular}

\section{Calorific power}

Table 5 shows the calorific values for diesel according to the literature. Table 6 shows the experimental values of the combustion power obtained for biodiesel samples. 
The average difference in favor of diesel oil is around 7\% since diesel oil contains aromatic hydrocarbons, which are elements that give high calorific value to this fuel. Comparing the calorific value of diesel with that of biodiesel, a slightly better performance of diesel is noted because the lower the calorific value of the fuel, the greater the mass required to release the same energy. These calculations are important in determining the expected consumption of biodiesel ${ }^{10}$.

Table 5 - Calorific power of diesel.

\begin{tabular}{ccc}
\hline Feedstock & $\begin{array}{c}\text { Calorific power } \\
(\mathbf{k J} / \mathbf{g})\end{array}$ & Source \\
\hline Diesel & 43.0 & {$[11]$} \\
\hline
\end{tabular}

Table 6 - Calorific power of samples.

\begin{tabular}{ccc}
\hline Sample & Mass $(\mathbf{g})$ & H $(\mathbf{k J} / \mathbf{g})$ \\
\hline BSGM & 0.5026 & $40.1 \pm 0.2$ \\
BSG & 0.5066 & $40.1 \pm 0.2$ \\
BSA & 0.4979 & $40.3 \pm 0.1$ \\
\hline
\end{tabular}

\section{Pour point and cloud point}

These parameters are of great importance for the study and consumption of products such as oils and their derivatives, because if these products are cooled to a low temperature they lose their characteristics and, in the case of biodiesel, can cause damages to the engine. Table 7 presents the values of the cloud point and pour point of the analyzed samples. As can be seen in Table 7, the pour point values differ between the samples. BSA is the most suitable sample for use at low temperatures without causing damage to the engine.

Table 7 - Comparison between the cloud point and pour point values of the samples.

\begin{tabular}{ccc} 
Sample & Cloud point $(\mathbf{K})$ & Pour point $(\mathbf{K})$ \\
\hline BSGM & $281 \pm 1$ & $278 \pm 1$ \\
BSG & $280 \pm 1$ & $277 \pm 1$ \\
BSA & $280 \pm 1$ & $274 \pm 1$ \\
\hline
\end{tabular}

\section{CONCLUSIONS}

The analyses in this study helped evaluate the physicochemical properties of biodiesel samples showing the great influence that temperature has on biofuels. This study evaluated the rheological behavior of distinct biodiesel samples, since biodiesel has been used on a large scale over the years. In some states, cold climate prevails, which does not favor the use of biodiesel, as in low temperature viscosity increases, hindering the engine work, leading to greater wear. The BSA sample would be recommended in cold regions due to the lower pour point.

The data explored by this work aims to bring solidification to methodologies and equipment necessary for a better characterization of biodiesel. Comparing the results obtained through the experiments carried out, it can be noticed that the commercial 
samples of the evaluated biodiesel have properties within the values specified by the ANP.

\section{ACKNOWLEDGMENTS}

We thank CNPq, CAPES, Fundação Araucária and UTFPR for funding and supporting this work.

\section{REFERENCES}

1- Ministério da Educação. Secretaria de Educação - Secretaria de Educação Profissional e Tecnológica. Biodiesel. Brasília. Novembro, 2006. Available from: http://portal.mec.gov.br/setec/arquivos/pdf/cartilha_biodiesel.pdf.

2- Knothe G, Steidley KR. Kinematic viscosity of biodiesel fuel components and related compounds. Influence of compound structure and comparison to petrodiesel fuels components. Fuel. 2005; 84(9): 1059-1065. Available from: https://doi.org/10.1016/j.fuel.2005.01.016.

3- Meher Lc, Sagar DV, Naik SN. Technical aspects of biodiesel production by transesterification - a review. Renew. Sustainable Energy Rev. 2006; 10(3): 248-268. Available from: https://doi.org/10.1016/j.rser.2004.09.002.

4- Salvi BL, Panwar NL. Biodiesel Resources and Production Technologies: A review. Renew. Sustainable Energy Rev. 2012; 16(6): 3680-3689. Available from: https://doi.org/10.1016/j.rser.2012.03.050.

5- Vicente G, Martínez M, Aracil J. Integrated biodiesel production: a comparison of different homogeneous catalysts systems. Bioresour. Technol. 2004; 92(3): 297-305. Available from: https://doi.org/10.1016/j.biortech.2003.08.014.

6- Alptekin E, canakci M. Determination of the density and the viscosities of biodieseldiesel fuel blends. Renew. Energy. 2008; 33(12): 2623-2630. Available from: https://doi.org/10.1016/j.renene.2008.02.020.

7- Carvalho HM, Ribeiro AB. Biodiesel: Vantagens e desvantagens numa comparação com o diesel convencional. Bolsista de Valor: Revista de divulgação do Projeto Universidade Petrobras e IF Fluminense. 2012; 2(1): 49-53. Available from: http://www.essentiaeditora.iff.edu.br/index.php/BolsistaDeValor/issue/view/102.

8- Agência Nacional do Petróleo, Gás Natural e Biocombustíveis. Resolução ANP No 45, de 25.08.2014. 2014. Available from: https://www.legisweb.com.br/legislacao/?id=274064.

9- Giap, SGE. The hidden property of Arrhenius-type relationship: viscosity as a function of temperature. J Phys Sci. 2010; 21(1): 29-39. Available from: http://web.usm.my/jps/21-110/16753402_21.1.3.pdf.

10- Zuniga ADG, Paula MM, coimbra JSR, Martins EcA, Silva DX, Telis-Romero J. Revisão: Propriedades físico-químicas do biodiesel. Pesticidas: r. ecotoxicol. e meio ambiente. 2011; 21: 55-72. Available from: http://dx.doi.org/10.5380/pes.v21i0.25939.

11- Simhadri K, chaitanya PS, Mohan GVD. Experimental analysis on performance improvement of diesel engine utilizing alternate fuels. Journal of Mechanical and civil Engineering. 2015; 12: 08-13. Available from: http://www.iosrjournals.org/iosrjmce/papers/vol12-issue1/Version-1/B012110813.pdf. 